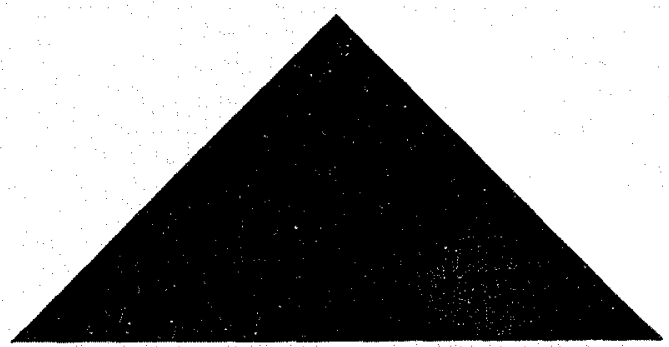

\title{
A LABORATORY INVESTIGATION INTO THE INTERACTION BETWEEN THE FLOW IN THE CHANNEL OF A RIVER AND THAT OVER ITS FLOOD PLAIN
}

\section{1. - Introduction}

Recent interest in flood-routing and the use of floodways has exposeed a lack of knowledge of the hydraulics of overbank spill. One problem in particular drew attention in an investigation conducted by the Bristol Avon River Board during 19571958. A model of the river's course through Bath, England, was constructed and run to investigate proposed flood alleviation measures. It was found that when the river rose above bank-full discharge the overbank flow reduced the velocities of the flow contained within the normal river channel. Hence the measured discharge of the model under these conditions was found to be less than the value given by the normally accepted method.

When the stage-discharge curve can be established by river gauging for all stages then this does not constitute a problem but frequently river gauging at overbank stages is either partially or totally impossible. Brown [1] stresses the dangers of extrapolating a gauged stage-discharge curve above any river stage at which sudden changes occur in the character of its cross-section. Parker [2] deals with the use of a stage-discharge curve based on an empirically established formula applied to a particular river by considering what amounts to its hydraulic radius. He illustrates this with a river

* Lecturer in the Department of Civil Engineering, Queen's University of Belfast.

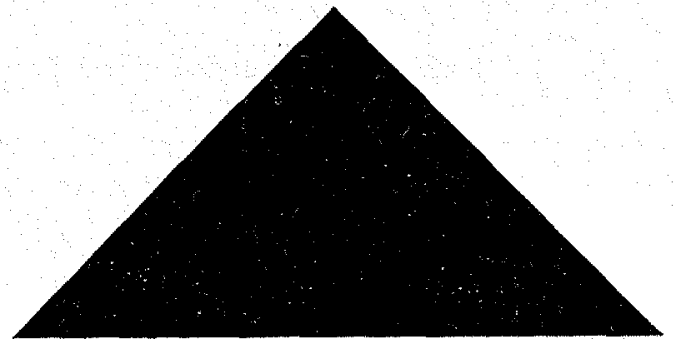

BY ROBERT HENRY JOHN SELLIN, B. Sc. Ph. D. *

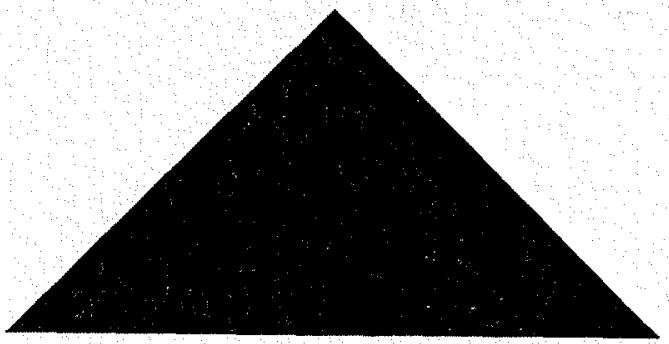

in which the main channel is flanked by a flood plain having a slope of $1: 20$ towards the channel. Had he taken a more nearly horizontal flood plain the dislocation in the resulting stage-discharge curve would have become clearly absurd. Taken to the limit an infinitely small depth of water on a horizontal flood plain of unlimited extent results in an overall hydraulic radius of zero regardless of the size of the river channel.

Houk [3], in his report to the Miami Conservancy district in 1918, deals with the computation of flood discharge by the area-slope method in great detail. He reviews all the stream flow formulae then available and evaluates them with reference to the Miami River flood of 1913, among others. Dealing with the discharge computations for overbank flow he states: "When the overflow area was wide and comparatively shallow, and the main channel narrow and deep... the overflow area was arbitrarily separated from the river channel and the discharge of each computed independently." When dealing with a river stretch in which the channel bank is marked by a well defined line of trees he includes a suitable vertical line in the wetter perimeter when computing the component hydraulic radii for the cross-section.

It will be shown in a later section that this method, which makes no allowance for interaction between the overbank flow and the channel flow, tends to overestimate the total discharge. This is particularly so when the overbank region contri- 


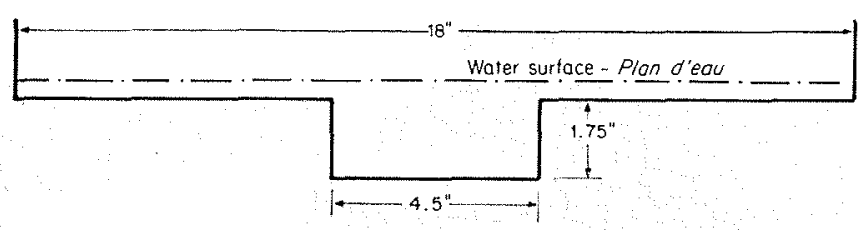

1/ Cross-section of Laboratory model.

Section transversale du modèle réduit.

butes only a small proportion of the total crosssectional area and when the depth of water on the flood plain is small compared with the bank-full depth of the channel.

\section{2. - Laboratory Investigation}

A laboratory investigation was planned to give experimental data on this interference process in the hope that rules might be developed that would

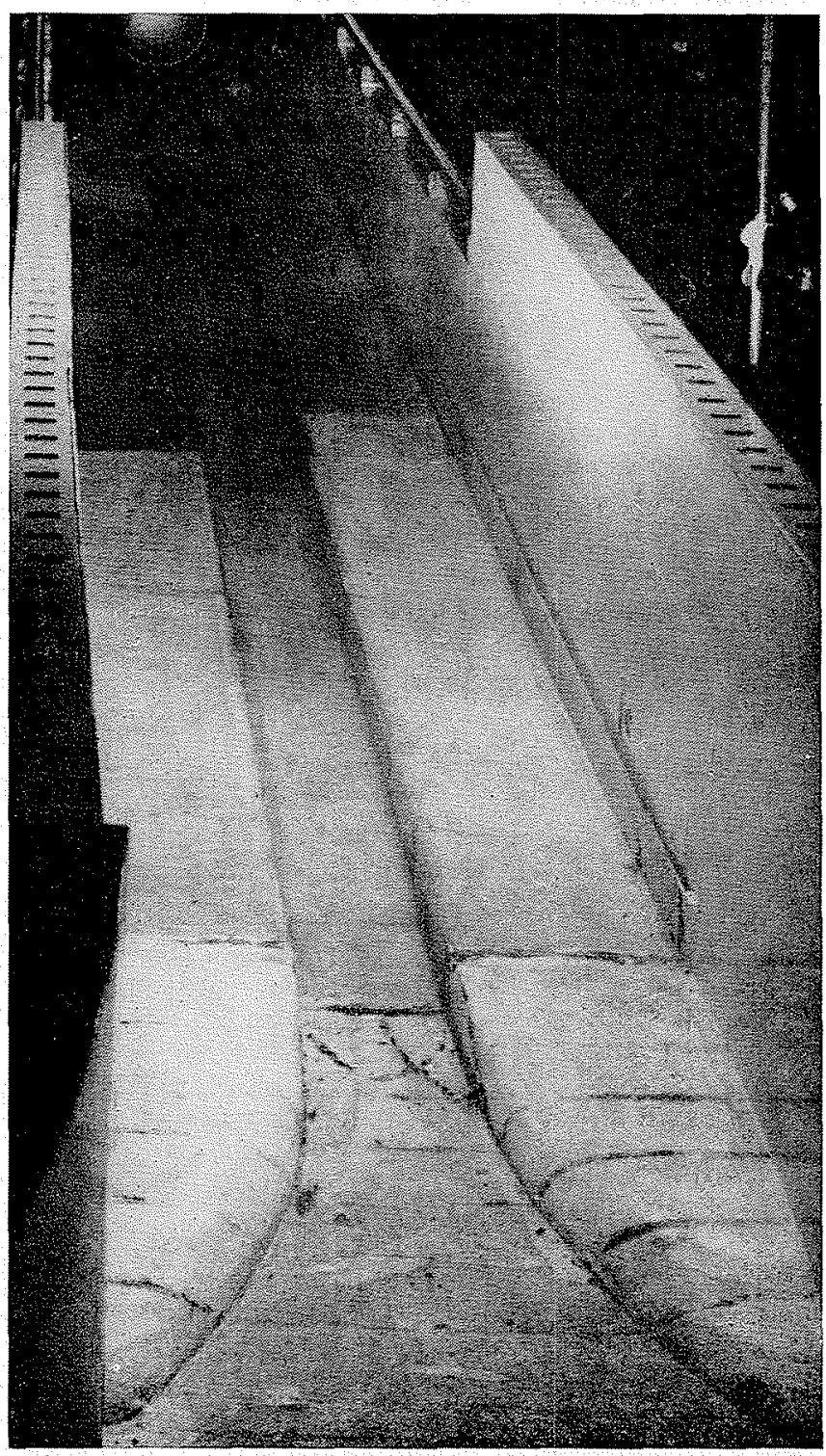

2/ Laboratory model from inlet end.

Extrémité amont du modele. give a more accurate estimation of flood discharges than was hitherto possible. A further object was the possibility of finding some means of suppressing this interaction and so increasing the capacity of the total cross-section.

The apparatus was designed to produce the maximum interference between the overbank or flood plain flow and the channel flow. Accordingly a rectangular channel section was chosen flanked symmetrically by a horizontal flood plain. The model accommodated a range or depth over the flood plain of from 0.1 or 0.3 times bank-full depth. The dimensions of the model cross-section are shown in Figure 1. The $15 \mathrm{ft}$. Iong model channel was straight and of constant cross-section. It was preceded and followed by double curvature transition sections $2 \mathrm{ft}$ long. Figure 2 shows the upstream end of the model.

Provision was made for the water surface profile or thalweg to be measured remotely. Groups of three interconnected static pressure tapping points were fitted at intervals of $42 \mathrm{in}$. down the length of the model. Each group consisted of one point on the centreline of the channel and one in each vertical wall in the same cross-section. The groups were connected to a bank of wide bore vertical glass manometer tubes in which the elevation of the water surface was measured using a traversing cathetometer.

The total discharge through the model was measured by an orifice plate meter in the supply pipe. Facilities were available for adjusting the slope of the channel. After trials a value of 0.00085 was found to be satisfactory and maintained throughout the experiments. The water surface elevation in the model was controlled by a variable tail weir, On account of the small slope of the bed, the run-down and backwater curves were found to be several times the lngth of the channel which made the condition of uniform flow in the model very closely dependent on the correct setting of the downstream weir.

\section{3. - Experimental Results}

Aluminium powder scattered on the water surface when the model was in operation revealed a strong vortex structure in the region of contact between the flood plain flow and that in the channel section. These vortex patterns were recorded by normal photography using a $35 \mathrm{~mm}$ camera attached to a travelling carriage. This was driven along rails parallel with the axis of the channel at a velocity adjusted to match the average velocity of the vortex cores.

Figures 3 and 4 show two of the resulting photographs. The twin white lines mark the junction of the channel section with the flood plain. Figure 5 shows a streamline pattern constructed from Figure 4 ad it must be remembered that this pattern is only relevant to an observer moving with the velocity of the camera carriage on that occasion. Hence in certain regions of the field in which it proved impossible to construct streamlines the surface velocity was equal momentarily to that of the "observer". 


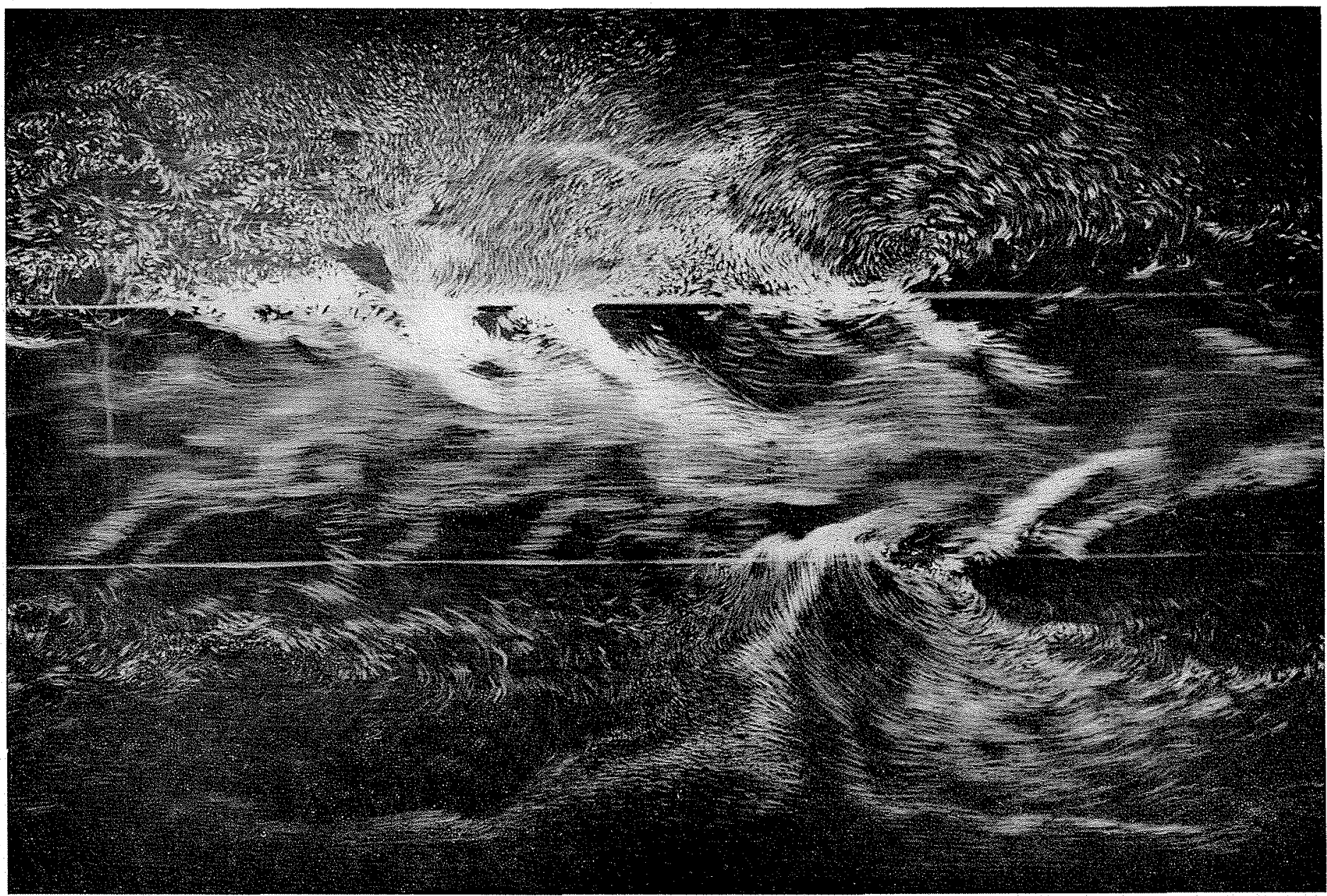

3/ Surface velocity pattern showing position of large vortices.
Répartition des vitesses à la surface, présentant d'importants tourbillons.
Although these surface photographs give a two dimensional streamline pattern of the flow it is clear, from the areas of concentration of the aluminium particles, where the principal vertical currents occur.

Approximately 80 such photographs were obtain- ed and 230 measured values of the spacing of adjacent vortices or pitch $\mathrm{P}$ were taken from them. Pitch values were expressed as a ratio $\mathrm{P}^{\prime}$ of the channel section and Figure 6 shows their frequency distribution. Curve (A) is constructed on a geometric grouping whilst curve (B) on an arithmetic

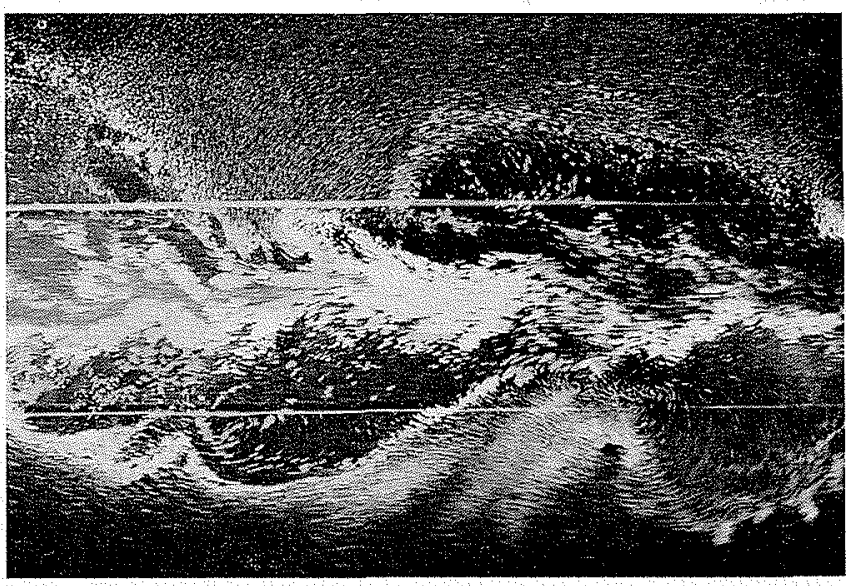

4/ Surface velocity pattern analysed in Figure 5. Répartition des vitesses, dont l'analyse est présentée dans la figure 5.

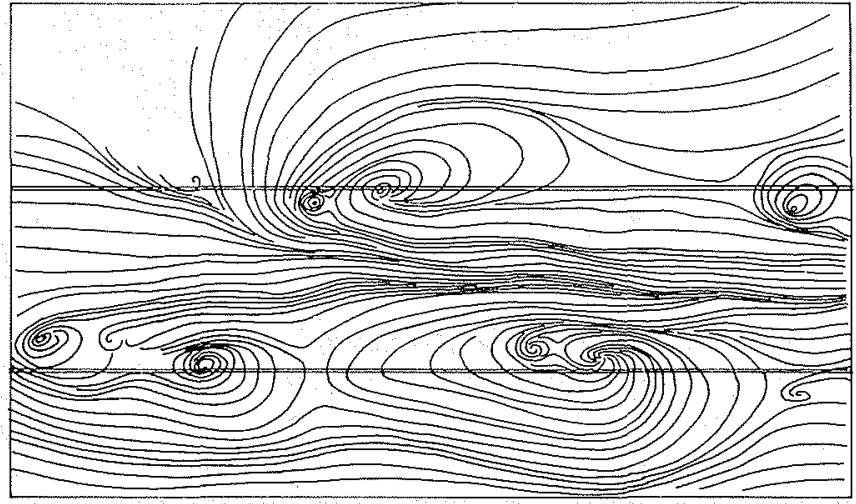

5/ Surface streamlines relative to moving camera, from Figure 4

Présentation des filets liquides superficiels, relativement à la caméra en monvement, d'après la figure 4 . 


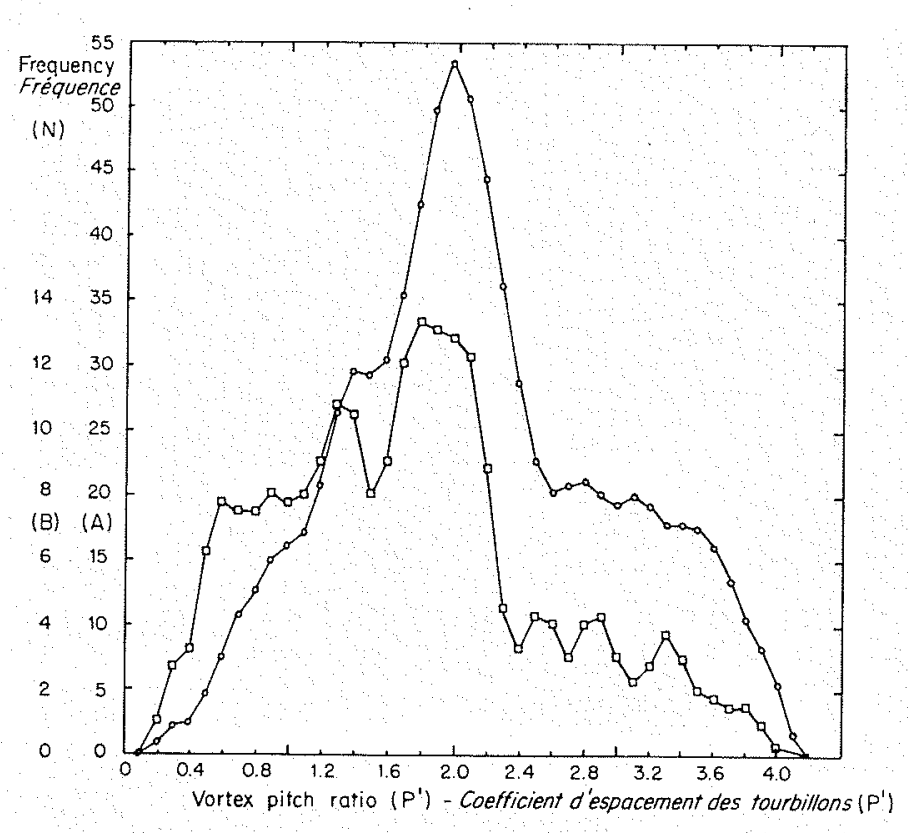

Curve $(A)-N$ taken as sum of occurences within $10 \%$ of $P^{\prime}$ value Curve $(B)-N \quad d^{\circ} \quad \ldots \quad 0,05$ - $d^{\circ}$ Courbe $(A)$ - N étant la fréquence des cas do $10 \%$ près de la valeur $P^{\prime}$ Courbe $(\mathrm{B})-\mathrm{N}-\mathrm{d}^{\circ}-0,05-\mathrm{d}^{\circ}-$

6/ Frequency distribution of vortex pitch ratio for flow in the model.

Répartition de la fréquence d'apparition des tourbillons de différents coefficients d'espacement, dans l'écoulement du modele.

basis. For the first $(\mathrm{N})$ is the sum of all values within $10 \%$ of the value of $\mathrm{P}^{\prime}$ and for the second (N) is the sum of all values within a fixed value $( \pm 0.05)$ of $\mathrm{P}^{\prime}$. Both curves reveal a marked peak at approximately $\mathrm{P}^{\prime}=2.0 \mathrm{but}$ the geometric arrangement of the data gives a more symmetrical distribution. It would be valueless to place any significance on the position of this peak without corroborative results from a range of channel widths.
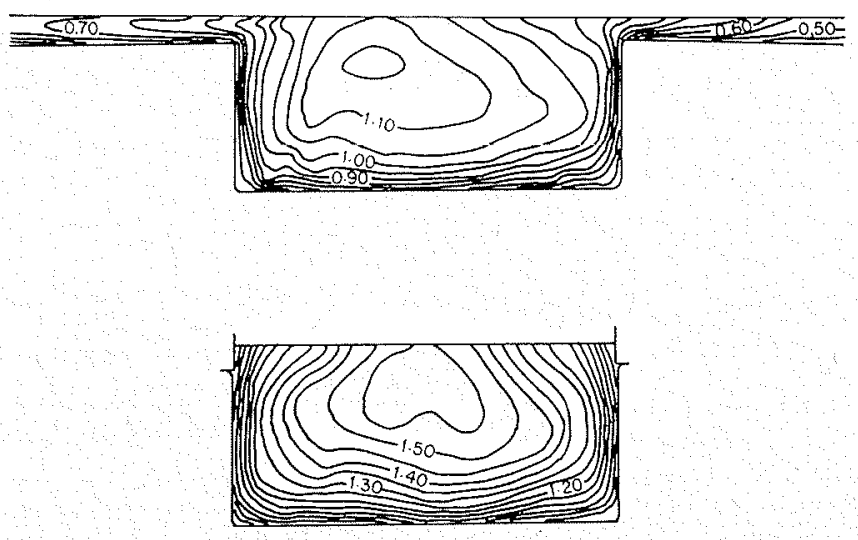

- Isovels plotted for velocity increments of $0.05 \mathrm{ft} / \mathrm{sec}$

- Courbes d'égale vitesse aux intervalles de 0,05 pied/s

1/ Mean longitudinal velocity distribution for central region of cross-section both with and without flood plain flow. Répartition moyenne des vitesses longitudinales, dans la partie centrale de la section, avec et sans écoulement dans le lit majeur.
The behaviour of these vortex patterns was also investigated using an optical system developed from the Schlieren principle which finds so many applications in the field of compressible fluid mechanics. A description of this technique appears elsewhere [4].

The study of surface flow patterns using aluminium powder photography revealed a momentum transfer mechanism operating between the flow in the channel section and that over the flood plain. In order to obtain quantitative data on the strength and influence of this mechanism. Pitot tube traverses were made to establish the cross-sectional velocity distribution. To determine the effect of the flood plain flow on the velocities in the channel section vertical longitudinal walls were introduced along either "bank" to confine the flow within the channel section. Then the measured velocity distribution with inundation of the flood plain prevented was compared with that in the channel section when normal flood plain flow occurred.

Figure 7 shows a corresponding pair of velocity distribution diagrams. The lower diagram represents flow of the same depth and water surface slope as the upper one but with the flow restricted to the channel section only.

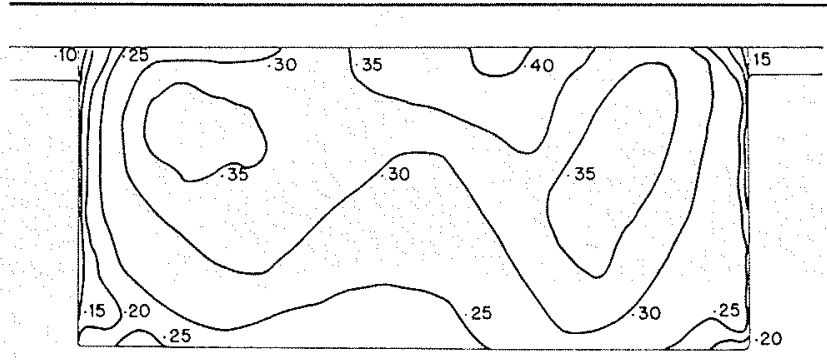

Velocity difference given as a proportion of the average point velocity for flow in the full cross-section. - Differences des vitesses, exprimëes comme pourcentage de lo vitesse ponctuelle moyenne, pour l'écoulement occupant l'ensemble de la section.

8/. Distribution of point velocity increases within the chan nel section due to the removal of the flood plain flow.

Répartition des augmentations des vitesses ponctuelles dans la section du canal, provoquées par. l'elimination de l'éconlement dil lit majeur.

Four corresponding pairs of velocity traverses were made combining two depths of flow with two positions of the cross-section along the length of the channel Considering only the velocity distribution within the channel section, the four distribution diagrams representing flow in the full crosssection were averaged and this average was then drawn as a single velocity distribution diagram. Similarly the velocity distributions without flood plain flow were condensed to a single diagram and Figure 8 represents the difference between the corresponding point velocities in these two condensed diagrams. High values are found close to either flood plain junction where they might be expected and also in the centre of the channel at the surface. This latter suggests that the presence of the momentum transfer mechanism either increases appreciably the secondary circulation in the straight channel section or else supplies it with relatively slow moving water from the flood plain.

The accuracy of the Pitot tube velocity values was checked by graphical integration of the velo- 
Table 1/ Analysis of velocity traverse data

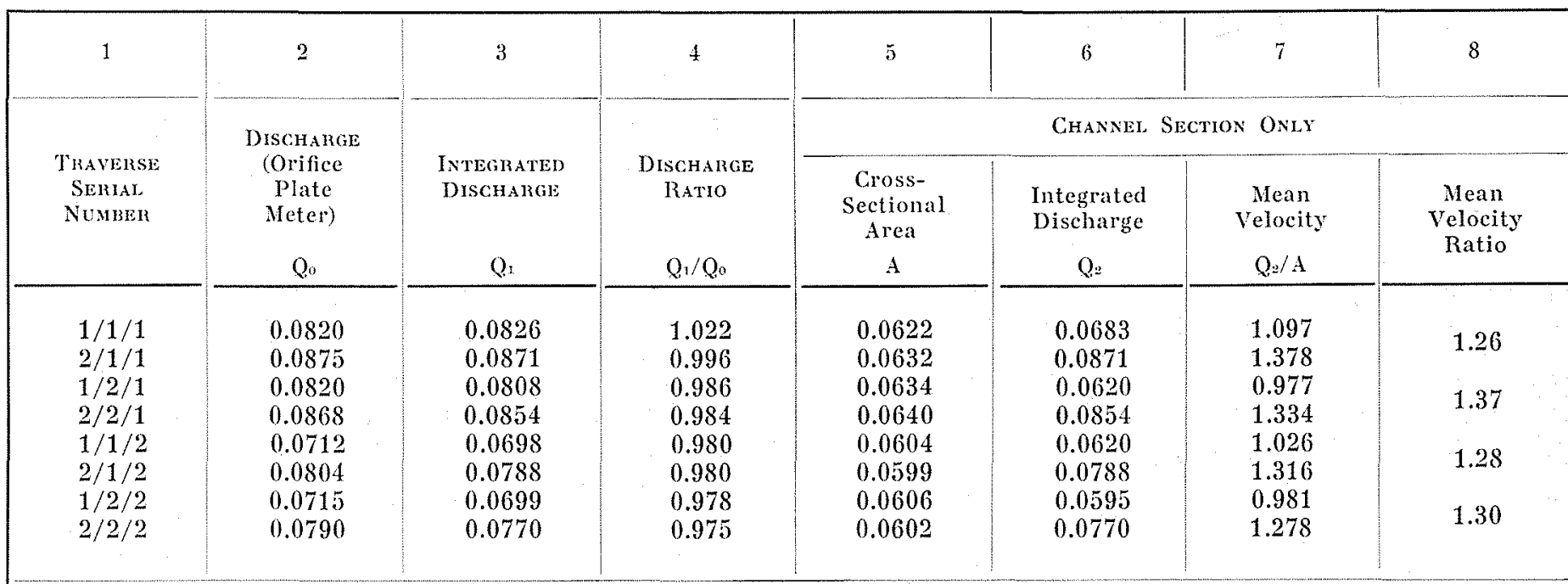

Notes :

1. Units in $\mathrm{ft}$, sec. and cusec.

2. Serial No.

1/ Flow in full cross-section.

/1/ Traverse station 11 ft from channel entry.

$/ 1$ Depth of flow $0.171 \mathrm{ft}$.
2) Flow in channel section only.

(2) Thaverse station $7 \mathrm{ft}$. $6 \mathrm{in}$. from channel entry. $/ 2$ Depth of flow 0.161 it. city distribution diagrams. These values (table 1 , column 3) when compared with the discharge values given by the Orifice plate Meter (column 2) show an average discrepancy of $-1.2 \%$. This may easily be accounted for by either the velocity coefficient of the Pitot tube, which was taken as unity, or to edge effects in the graphical integration process.

Columns 5-8 are concerned with flow conditions in the channel section. In the traverse represented by the first line in each pair the flood plain flow was present and in the second it was not. Column 8 then shows the effect of the flood plain flow on the ratio of the corresponding mean velocities in the channel section. The mean of these four ratios shows a $30 \%$ average increase (S.D. $3 \%$ ) in velocity in the channel section when the flood plain flow is removed.

In order to investigate this interference mechanism at all depths of flow the stage-discharge relationship was determined under varying conditions. From these, mean velocities were computed and corresponding maximum velocities were found using a small propeller meter set in the centre of the channel section just below the surface.

In Figure 9 curve (1) represents the stage-discharge relationship for the full cross-section. Plotted to a double logarithmic base the points are seen to lie quite close to one or other of two straight lines.

Figure 10 shows to a larger scale the detail of the transition region in the stage-discharge relationship for the full cross-section. It will be seen that within a certain range of discharge there are alternative depths of flow, the lower siving uniform flow, when equilibrium conditions are approached from below and the upper when approached from above. This suggests a sharp increase in the re- sistance to flow when inundation of the flood plain occurs.

Curve (2) in Figure 9 shows the stage-discharge relationship for flow in the channel section alone. The inexplicable result of this experiment is that the discharge through this reduced section is greater than that in the full cross-section at all depths of flow investigated. In the former case the additional wetted perimeter consisted of extruded alu-

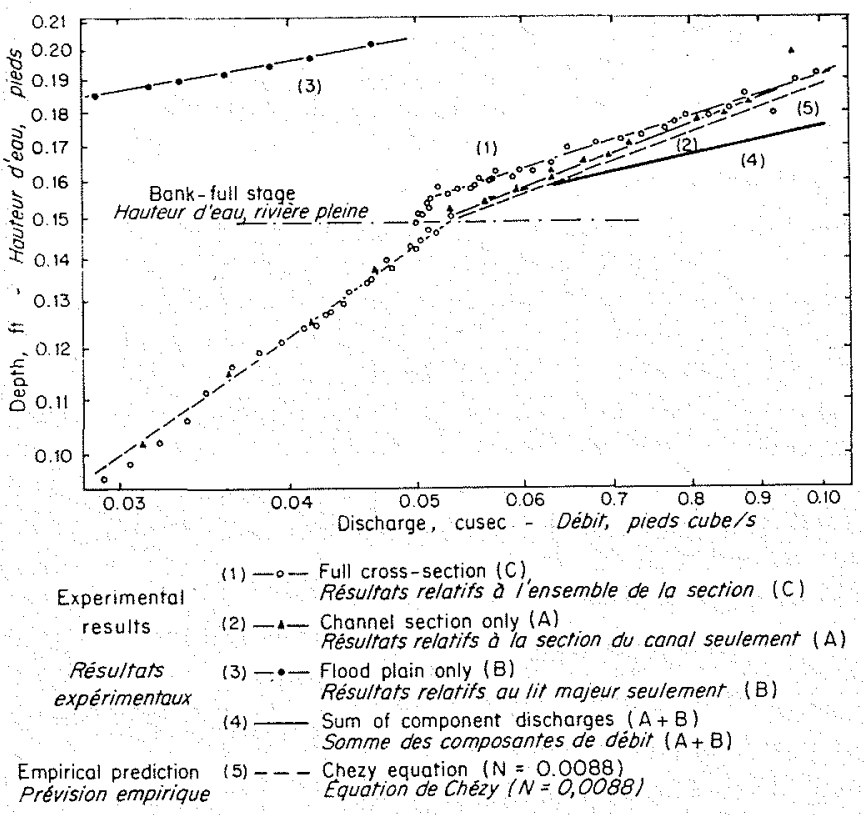

9/ Discharge of the full cross-section compared with that of the cross-section elements and the Chézy equation.

Comparaison du débit global de la section et de ceux correspondant aux différents éléments dont elle se compose, et du débit découlant de l'équation de chézy. 
minium alloy sections having a surface finish apparently very similar to hte smooth fibre-glass surface of the original cross-section. The experimental points lie, with only one exception, close to a straight line on this log. graph and were determined in a precisely similar manner to that used in the other tests.

Curve (3) represents the stage-discharge relationship for the flood plain with the centre channel section blocked off. Because of the shift of origin in the ordinate this curve will be asymptotic to the horizontal line representing bank-full depth in the channel section.

The sum of these two component discharges is represented by curve (4) in Figure 9. This represents the actual discharge of the full cross-section with complete isolation of flood plain and channel section flows.

Curve (5) represents the stage-discharge relationship predicted by the Chezy formula used in the manner outlined above. It predicts discharges 10$12 \%$ in excess if the measured values (1) for depths just greater than bank-full.

Figure 11. shows mean and maximum velocities for the full cross-section plotted against depth of flow in the channel. The effect of the momentum transfer mechanism in reducing velocities in the channel section, seen already in Figures 7 and 8 , is brought out clearly by curve (7). The mean velocity - curve (6) - is less sharply affected because the reduction in velocity is not so great in other regions of the cross-section (see Figure 8). The difference between these two curves is greatest when the depth, and therefore the velocity, on the flood plain is small.

The various mean velocity and discharge values found so far are expressed as ratios in Figure 12. Curve (8) shows the ratio of the mean velocity of flow in the channel section alone to that in the full cross-section. Curve (9) is based on the ratio of the sum of the discharges in the channel section and flood plain obtained separately to that in the full cross-section. The final curve (10) shows the ratio of the discharge in the channel section alone to that in the full cross-section at the same depth. The abscissa shows the depth of flow in the channel section but only above bank-full depth.

The foregoing results show how the complete isolation of the flood plain flow from the channel section flow increased the total discharge capacity of the model. In the general case, however, of a non-uniform cross-section the relative capacities of the channel section and the flood plain on either hand would vary from one section to another and so it would be essential to provide for a nett flow of water across the channel banks. Even in the event of a uniform cross-section the rapidly changing stage of a river in flood would require this transverse flow. Therefore it appears that if any practical benefit is to be obtained from some form of isolating wall (flood wall) this must permit a moderately free passage of water.

The first type of permeable flood wall investigated in the model consisted of a row of vertical cylinders. The resulting stage-discharge curves, (11) and (12), are shown in Figure 13. It can be seen from this figure that at no depth is there any perceptable increase in discharge as compared with the

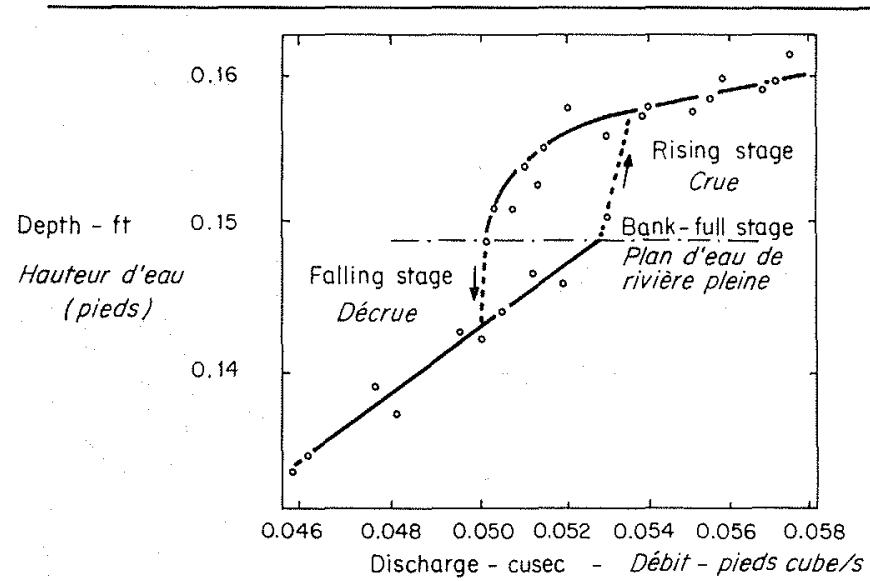

10/ Details of transition region in the stage-discharge relationship for flow in the full cross-section.

Zone de transition de la loi hauteur/débit, correspondant d̀ l'écoulement dans l'ensemble de la section.

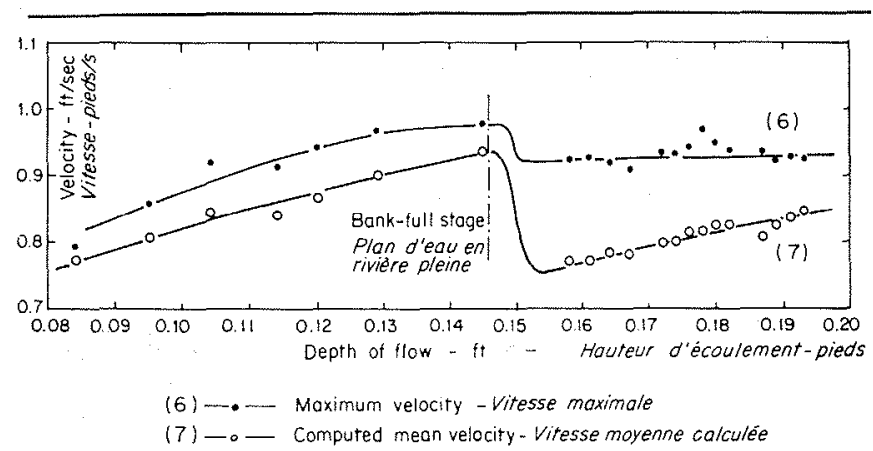

11/ Velocity-stage relationships for flow in the full crosssection.

Variation des vitesses en fonction des hauteurs d'eau, pour l'écoulement occupant l'ensemble de la section.

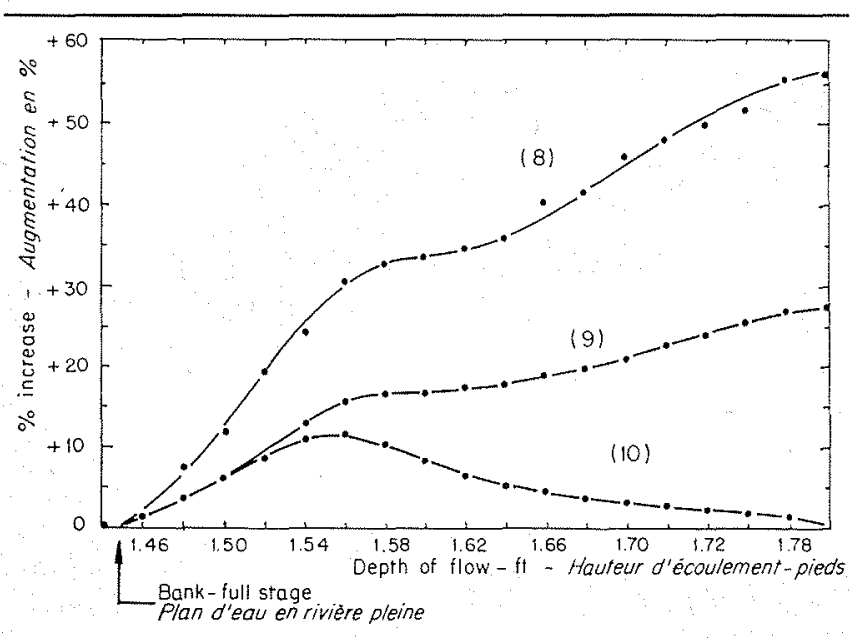

(8) Mean velocity ratio: channel section only $(A)$

"Rapport des vitesses moyennes: section du canal seulement (A)

(9) Dischorge ratio: $\frac{\text { component elements }(A+B)}{\text { full cross-section }}$

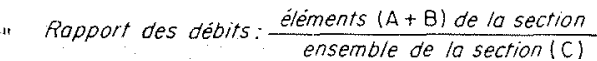

(10) Discharge ratio: $\frac{\text { channel section only (A) }}{\text { full cross-section (C) }}$

". Rapport des débits: $\frac{\text { section du canal seulement }(\mathrm{A})}{\text { ensemble de la section }(\mathrm{C})}$

12/ Percentage increases in discharge and velocity produced by isolating the flood plain flow.

Pourcentage d'augmentation du débit et de la vitesse provoquée par l'élimination de l'écoulement dans le lit majeur. 

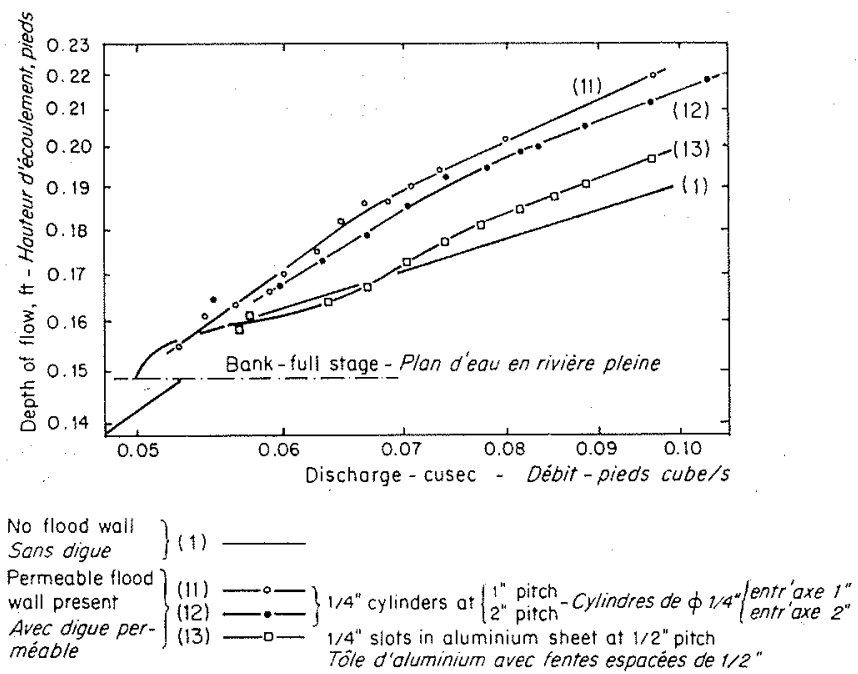

13/ Channel discharge modified by the introduction of various permeable flood walls (flood plain unroughened). Modification du débit du canal par l'introduction de différentes digues perméables (lit majeur non rugueux).

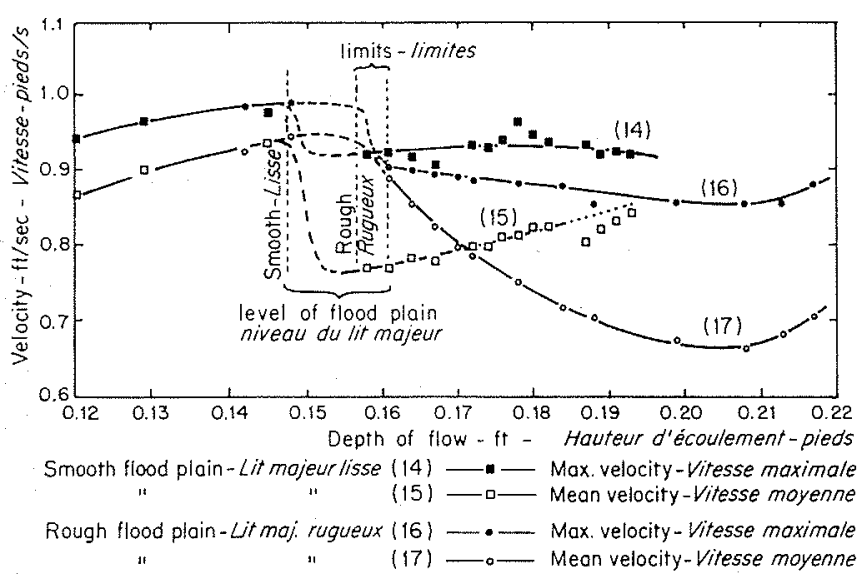

14/ Effect of flood plain roughness on maximum and mean channel velocities.

Influence de la rugosité du lit majeur sur les vitesses maximales et moyennes dans le canal.
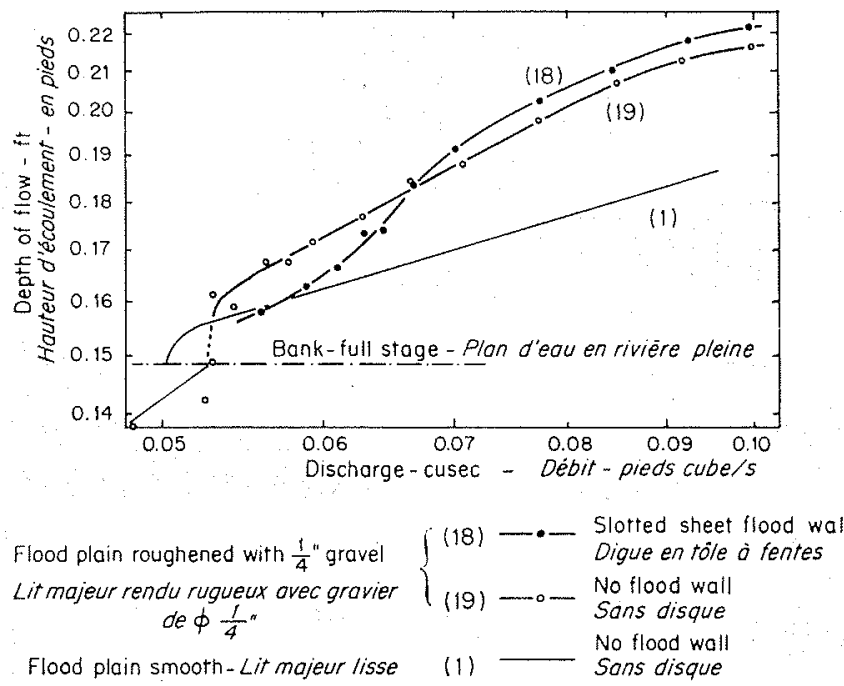

15/ Stage-relationships for model with flood plain roughened.

Lois hauteur/débit pour le modèle comportant un lit majeur rugueux. capacity of the simple cross-section (1). Rather, there is a decrease in capacity of between 10 and $20 \%$. It was realized that this form of flood wall would produce a very considerable resistance to flow which was clearly far in excess of any possible benefit due to a reduction in the momentum transfer mechanism.

The next flood wall to be investigated was constructed from a $0.012 \mathrm{in}$. thick sheet of aluminium alloy by removing $1 / 4 \mathrm{in}$. wide vertical strips at $1 / 2$ in. intervals. This permeable flood wall then presented a very small projected area in the principal direction of flow and $50 \%$ permeability normal to this. The resulting stage-discharge relationship is shown by curve (13) and it will be seen that a slight increase in capacity is achieved at low flood plain depths.

In the experiments so far completed the flood plain surface finish was indistinguishable from that of the channel section. This surface had been found to have a "Manning" roughness number of 0.009 and so may reasonably be considered as "hydraulically smooth". However, since a natural flood plain may be expected to be considerably "rougher" than a natural river channel, a number of the experiments were repeated with the model flood plain roughened.

Crushed stone (passing a $1 / 4$ in. sieve and retained on the next smaller size) was spread over the flood plain to form a closely packed layer of unit thickness. This raised the level of the flood plain by an amount varying between 0.009 and $0.013 \mathrm{ft}$. so making a sharp definition of bank-full depth no longer possible. The shape and size of the particles used indicate a flood plain roughness number of 0.019 .

The change in flow conditions brought about by the flood plain roughening is most clearly shown by the mean and maximum velocity values which are plotted against depth of flow in Figure 14 . Curves (14) and (15) show for comparison the maximum and mean velocities under smooth flood plain conditions while (16) and (17) are with the flood plain roughened. It is interesting to note how the mean and maximum values draw apart with increasing depth when the flood plain is roughened while the reverse occurs with the flood plain in its original condition.

Since, in a roughened state, the flood plain is found to exert a greater influence on the velocities of the cross-section it would seem reasonable to expect a proportionately greater benefit, in terms of increased capacity, from the use of a permeable flood wall.

The stage-discharge curves for the channel with the flood plain roughened are shown in Figure 15 both with and without the slotted aluminium flood wall. A distinct increase in discharge is now produced by the permeable flood wall between depths of 0.16 and $0.18 \mathrm{ft}$. in the channel section.

This increase in discharge is expressed more directly and compared with the corresponding increases obtained with the original flood plain surface in Figure 16. Whereas the smooth flood plain could only yield at the most a discharge increase of between 3 and $4 \%$, in its roughened state the permeable flood wall resulted in a maximum increase of $10 \%$ combined with appreciable increases 


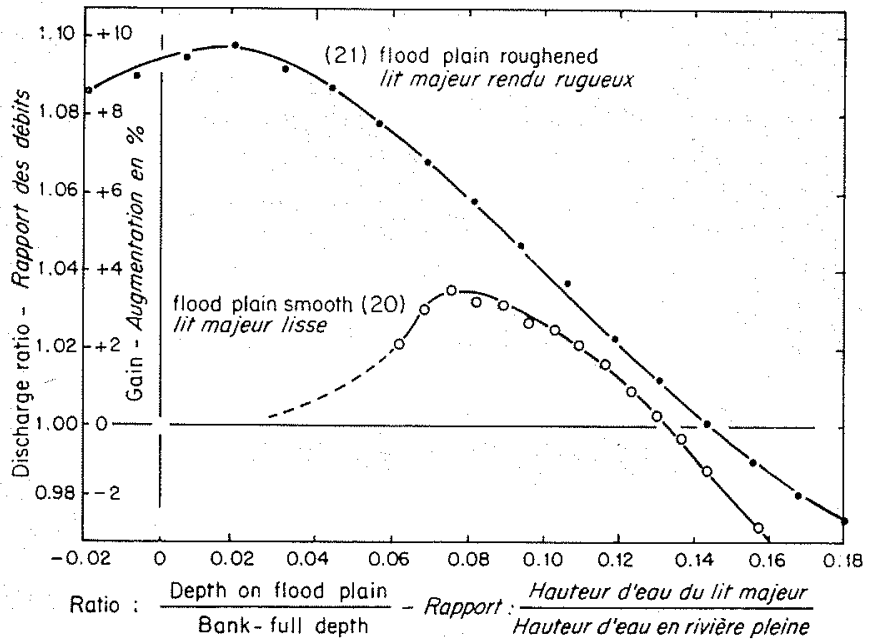

16/ Increases in discharge due to isolation of flood plain by slotted flood wall.

Augmentation du débit due à l'isolement du lit majeur au moyen d'une digue à fentes.

over a much greater range of depths. In this figure the increase of discharge is plotted against the ratio of the depth on the flood plain to the bankfull depth. This overcomes the difficulty of making comparisons when the flood plain level is not the same in the two cases.

\section{4. - Conclusions}

In the first section of this paper the Author reviewed some of the methods at present available for the computation of flood discharge involving overbank flow. It would now be of value to compare the measured performance of the laboratory model with its estimated discharge using these alternative methods.

Since the Chezy-Manning discharge formula has been found [3] acceptable for small and medium sized channels it will be used in the present instance. For this purpose the cross-section is specified by the hydraulic radius, $R$, and the Manning/Kutter roughness number, $n$. Therefore, for any given value of $n$ the discharge will simply be a function of $R$ and it will be sufficient in the present circumstances to investigate values of $R$ mnder the various conditions.

Figure 17 shows the hydraulic radius plotted against depth of flow in the channel section. Curve (22) shows values of $\mathrm{R}$ calculated without any modification of the usual method as are all the values of $R$ at depths below bank-full stage. As stated in $\$ 2$ this results in an interruption in the function at bank-full stage. The magnitude of this dislocation depends upon the ratio of the overall flood plain width to the width of the channel section. Even with the relatively narrow flood plain of the model cross-section the value of $R$ is reduced by $65 \%$ at this point. Curves (23) I, II and III represent slight variants on the normal discharge estimation procedure (see above) which avoids this numerical break at bank-full stage. Of these alternatives (23) II is the most common but (23) I has been found satisfactory [5] when considerable depths on the flood plain have been encountered.

Curve (24) is drawn through points deduced from the experimentally determined stage-discharge curve (1), Figure 9. In making these calculations a value of 0.0088 for $n$ was used which was determined experimentally in the depth range just below bank-full. It will be seen that these points agree quite closely with curve (23) I at the upper limit of the values obtained but that at lower flood plain depths the discrepancy is considerable (up to $25 \%$ ). Thus, to take the extreme case, the computed hydraulic radius for low depths on the flood plain would lead to an estimated discharge $19 \%$ in excess of the actual figure. Although this is obviously an extreme case operating under the most adverse circumstances it indicates that the effect of this momentum transfer mechanism on flood discharge estimation should not be ignored.

As an alternative approach values of $R$ were taken from curve (23) II and used together with the experimental stage-discharge values in the Chezy-Manning formula to give values of $n$. The resulting variation of $n$ with depth of flow is shown by curve (25) in Figure 17. The experimental points for below bank-full depths represent the normal treatment of a regular cross-section with the points approaching a steady value of 0.0088 . As the depth of flow increases the momentum transfer mechanism produces a sudden increase in the roughness number ( $n$ increased by approximately $12 \%$ ). As the depth of flow on the flood plain

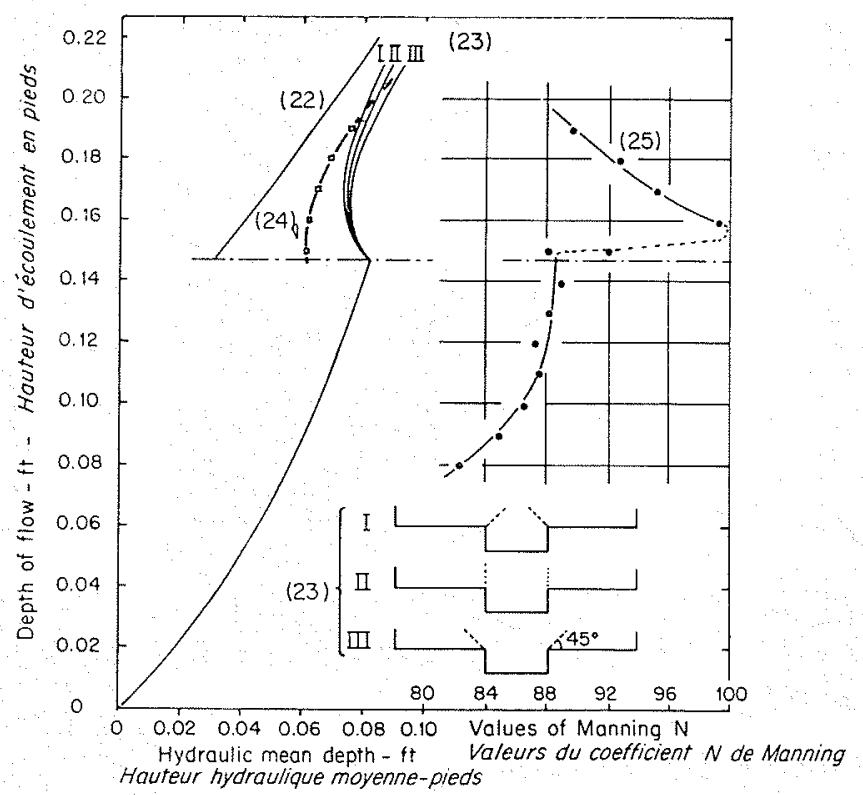

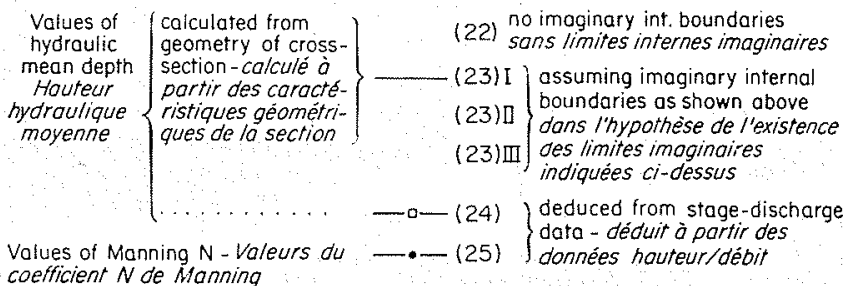

11/ Calculated and deduced values of hydraulic mean depth and "Manning $N$ ".

Valeurs calculées et déduites, de la hauteur hydrauliques moyenne et du coefficient $N$ de Manning. 
increases further these values return quite rapidly to the below bank-full value showing that the procedures adopted in calculating curve (23) II is adequate under these conditions.

From this it appears that a satisfactory procedure for improving the accuracy of overbank flow estimates might lie in some empirical weighting of the roughness number. However, insufficient data was obtained from the present experiments to make possible any firm recommendations. Further experimental data is required on the effect of variations of scale, cross-section shape, and flood plain and channel roughness before the effect of the momentum transfer mechanism can be expressed numerically in anything approaching specific terms.

It was found that the presence of a permeable flood wall in the laboratory model reduced the strength of the momentum transfer mechanism. However, the actual effect of this flood wall upon the flow resistance depended upon its own drag, and the velocity in the channel section was only increased if the suppression of the momentum transfer mechanism more than compensated for the drag of the flood wall itself.

Without experiments in different size models it is only possible to speculate upon the effectiveness of such a structure in the field. The slotted flood wall was tested under different flood plain roughness conditions and showed an increase in effectiveness for an increase in roughness. This suggests that a higher Reynold's number, and hence more fully developed turbulence, would also increase the effectiveness of the flood wall.

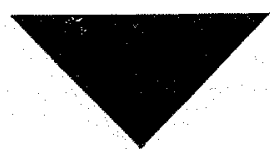

Acknowledgements

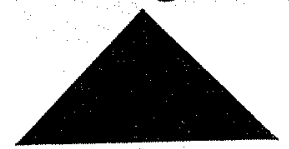

The Authors wishes to records his tanks to Professor Sir Alfred Pugsley, O.B.E., F.R.S., D.Sc, and Dr. E.F. Gibbs (both of the University of Bristol, under whose general supervision this work was carried out) for their interest and encouragement.

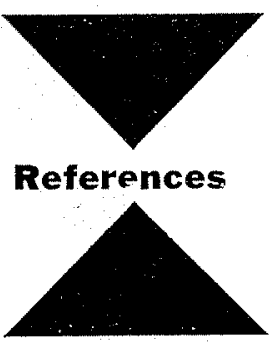

[1] Brow (J.G.) (Ed.). - Hydro-electric engineering practice. Blackie, London (1958), Vol. I. p. 68.

2] PARISER (P.A.M.). - The control of water. Routledge and Kegan Paul, London (1949), p. 91.

[3] Houk (I. E.). - Calculation of flow in open channels. Technical Report (pt. IV) for the Miami Conservancy district, Ohio (1918).

[4] Selliv (R. H.X.). - A technique based on the Sehlieren principle for studying the surface of a liquid. $J$. of Sci. Instr., Vol. 4.0 (July 1963), pp. 355-7.

[5] Mrrchesu (W.D.). - Stage-fall-discharge relationships for steady flow in prismatic channels. U.S. Geologica Survey, Water Supply Paper, No. 1164.

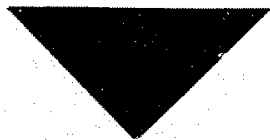

Résumé

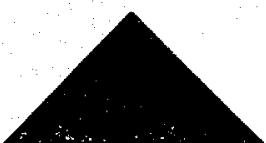

\title{
Etude de l'interaction entre l'écoulement dans le lit d'une rivière et l'écoulement dans son lit majeur
}

\author{
par R.H.J. Sellin *
}

Cet article expose les résultats d'une étude expérimentale de l'interaction entre l'écoulement dans le lit d'une rivière et celui au-dessus de la plaine d'alluvions, quand la rivière est en crue. Le modèle de laboratoire possède une section centrale profonde (le lit) flanquée symétriquement par les plaines d'alluvions horizontales et peu profondes.

\section{Mécanisme de transport de quantité de mouvement.}

On expose qu'un intense mécanisme de transport de quantité de mouvement existe dans la région où la plaine d'alluvions rejoint le lit; ce mécanisme a été étudié qualitativement par photographie de poudre d'aluminium (voir fig. 3 et 4). Des mesures faites au moyen de tubes de Pitot montés sur traverses avec ou sans inondation de la 


\section{R.H.J. SELLIN}

plaine d'alluvions montrent à quel point l'action de ce mécanisme de transport de quantité de mouvement abaisse les vitesses et, par conséquent, le débit de la section centrale (voir fig. 8).

Une relation expérimentale niveau-débit est employée pour obtenir des résultats plus détaillés à cet égard et aussi pour étudier la possibilité d'augmenter le débit de la section transversale entière par la suppression de ce mécanisme. Des digues perméables de diverses sortes sont employées à cette fin et donnent des résultats variables (fig. 13). Finalement, on a rendu plus rugueuse la plaine d'alluvions et on a constaté que cela favorise le mécanisme déjà observé. L’usage desdites digues perméables conjugué avec l'augmentation de rugosité de la plaine d'alluvions a augmenté de $10 \%$ le débit de la section transversale tout entière (voir fig. 15 ).

\section{Remarques générales.}

Les méthodes normales de projet pour calculer le débit de crue sont discutées et employées pour prévoir le débit du modèle (voir fig. 17). Les différences entre ces prévisions et les débits expérimentaux sont examinées et on fait des suggestions pour calculer plus exactement le débit de crue en partant des mesures de niveau. L'action du mécanisme de transport de quantité de mouvement, employant les résultats expérimentaux, est modifiée par un changement apparent du $n$ de Manning avec le niveau (voir fig. 17, courbe 25). Les limitations inhèrentes à une recherche de laboratoire rendent difficiles des recommandations trop précises.

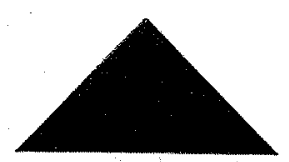

